\title{
A REVIEW ON MECHANICAL PROPERTIES OF NATURAL FIBRE REINFORCED CONCRETE FOR RIGID PAVEMENTS
}

\author{
M.Venkata Naga Prasad ${ }^{1}$, Dr.J.Sridhar ${ }^{2}$ \\ ${ }^{\text {I}}$ PG Scholar, Transportation Engineering, GMR Institute of Technology-Rajam, Andhra Pradesh, \\ India. \\ ${ }^{2}$ Associate Professor, Dept. of Civil Engineering, GMR Institute of Technology-Rajam, \\ Andhra Pradesh, India.
}

Article DOI: https://doi.org/10.36713/epra8563 DOI No: 10.36713/epra8563

\begin{abstract}
This study focuses on fiber reinforcement, specifically the use of jute and coir as a fiber reinforcing material in concrete. Natural fibers have been used to provide substantial toughness and strength in a very fragile cement matrix composite. It is necessary to make effective changes in this regard. Uses a very alkaline cement matrix to achieve durability. It is preferable to have a chemical composition that is clear. Reinforce the cement and change the surface of the fibers composite. The usage of jute fiber in this article is discussed. Concrete and the impact it has on the characteristics of the concrete it produces, for example this is an attempt to review the work that has just been completed. In the discipline, as well as to establish a foundation for future study in that case. It is critical to create low-cost building and reinforcing techniques that are suited for developing countries. If agricultural byproducts like coconut coir can be used to replace steel bars as reinforcement, building costs can be reduced. Down significantly the purpose of this study is to evaluate the characteristics of coconut fibers. Species produced in India and their uses in many fields of engineering, notably civil engineering enhancing the long-term durability of concrete and mortar using engineering as a building material with the addition of coconut fibers the overall objective is to look into the possibility of utilizing domestic resources. Wastes for construction on a tiny scale a review of several researchers' experiences utilizing is presented in this publication. The performance of coconut coir as a reinforcing component is explored in depth.
\end{abstract}

\section{INTRODUCTION}

Road networks serve as the nation's arteries in a developing country like India. Vehicles move on a pavement, which is a layered structure. It has two purposes: to create a comfortable and long-lasting driving surface for cars, and to relieve stress on the underlying soils. Bituminous pavement is a commonly utilised traditional technique in India. Bitumen is a by-product of the distillation of imported petroleum crude, and locally produced cement concrete is a superior replacement. Petroleum and its by-products are a well-known reality that are rapidly depleting. In India, if we think about road building, we assume it would be a bituminous pavement, and there are relatively few opportunities to consider alternatives such as concrete pavements. Bituminous pavement will be obsolete in two to three decades, necessitating the development of a viable replacement. Concrete's strength and durability may be altered by altering its constituents, such as cement, aggregate, and water, as well as by adding specific additives. As a result, concrete is ideally adapted to a variety of uses. Concrete, on the other hand, has some flaws, including poor tensile strength, low postcracking capacity, brittleness and low ductility, limited fatigue life, inability to accommodate significant deformations, and low impact strength. Brittle failure, or the loss of virtually all loading 


\section{EPRA International Journal of Research and Development (IJRD)}

Volume: 6 | Issue: 9 | September 2021

- Peer Reviewed Journal

capability, is a characteristic of cement concrete. This property, which limits the material's application, can be overcome by adding a small amount of short randomly distributed fibres (steel, glass, synthetic, and natural) to the mix, which can be used to address concrete flaws such as low growth resistance, high shrinkage cracking, and low durability, among other things. Plain concrete has an inherent fragility due to the existence of tiny fractures at the mortar-aggregate interface. By incorporating fibres into the mix, the weakness can be eliminated. To improve the concrete's toughness, or capacity to resist fracture development, other types of fibres, such as those utilised in conventional composite materials, have been included into the mix. The fibres aid in the weight transmission at the tiny fractures inside the body. Fibre-reinforced concrete is a type of concrete like this (FRC). Fibre-reinforced concrete, then, is a composite material made up mostly of ordinary concrete or mortar reinforced with fine fibres.

\section{LITERATURE REVIEW}

Mehran khan et.al (2020): Natural fibres with concrete can produce a more durable and costeffective infrastructure. The coconut fibre (CF) has the highest toughness of all natural fibres. Using American Concrete Pavement Association street pave software, this study explores the use of coconut fibres in concrete with silica fume, from composite material qualities through concrete road design.

Masakazu terai et.al (2011): The viability of employing bamboo and non-steel as reinforcing materials in concrete members is presented in this study. This study was written to aid in the seismic retrofit of masonry structures as well as the design and construction of bamboo reinforced concrete structures.

Summit Chakraborty et.al (2012): Jute fibre is used as a reinforcing material in cement mortar to improve its physical and mechanical qualities. The jute reinforcement greatly improves the physical and mechanical qualities of cement mortar, according to the researchers. The flexural toughness and toughness indices of fibre reinforced mortar specimens prepared utilising the PS3 technique were also significantly improved.

Hemanth Kumar et.al (2017): This research looks at how natural fibres affect the mechanical properties of epoxy composites. The adhesion between the matrix and the fibres has a big impact on the mechanical properties of composites. Natural fibres (cane sugar) combined with chopped glass fibres were found to increase the mechanical properties of hybrid composites.

Nico's Ali Libre et.al (2010): Natural pumice as coarse aggregates can be used to make structural LWAC with a density of $1740-1880 \mathrm{~kg} / \mathrm{m} 3$ and a compressive strength of $19-30 \mathrm{MPa}$, according to this paper. Fibres were employed to help minimise LWAC's brittleness. The goal of this research is to use hybrid steel and polypropylene fibres to improve the ductility of pumice light weight aggregate concrete.

A.V. Ratna Prasad et.al (2011): In this paper, the experiments of tensile and flexural tests were carried out on composites made by reinforcing jowar as a new natural fibre into polyester resin matrix. This composite material has been discovered to be roughly similar to bamboo composite in tensile strength and 1.89 times stronger than sisal composite in tensile strength. Jowar composite has a flexural strength of 4 percent, a tensile strength of 35 percent, and a flexible modulus that is 1.12 times and 2.16 times greater than that of bamboo and sisal composites, respectively.

Emmanuel owoichoechi momoh et.al (2020): Based on this research, it has been discovered that the fibres have a specific gravity range of 0.45-0.84, with a diameter ranging between 0.20 millimetres (at the tail) and 4.00 millimetres (at the cap), as well as a maximum strength of $900 \mathrm{MPa}$ (at the cap). Understanding the effects of moisture content and age on the physical and mechanical properties of OPBF will help researchers better understand the material's behaviour and make more informed decisions about its potential applications in polymeric and cement composites, among other things.

V.Fiore et.al (2014): An investigation of the effects of alkaline treatment (6 percent $\mathrm{NaOH}$ solution) on the mechanical characteristics of kenaf fibres and their epoxy composites was conducted in this work. Results of the tests demonstrate that the alkali treatment increases interfacial adhesion between the fibre matrix and polymer chains, hence decreasing the mobility of polymer chains and increasing stress transfer. Furthermore, the alkali treatment improved the compatibility of the fibres and the matrix of the composites, resulting in an increase in their mechanical properties.

Soon Poh Yap et.al (2015): The use of oil palm shell (OPS) as a substitute for traditional coarse aggregate results in a greener structural light weight aggregate concrete that is lighter in weight and more durable 


\section{EPRA International Journal of Research and Development (IJRD)}

(LWAC). Steel fibres improve the mechanical qualities of LWAC, which includes OPS concrete, by a significant amount (OPSC). In this study, we investigate the effects of the aspect ratio $(1 / \mathrm{d})$, as well as the volume fraction (VF), of hooked end steel fibres in oil palm shell fibre-reinforced concrete (OPSFRC). This mixture has an 83 percent increase in splitting strength when compared to the control mix, which was achieved by using the maximum $1 / \mathrm{d}$ ratio. Mechanical properties were generally enhanced with an increase in VF from 0.25 percentage point to 0.75 percentage point. According to the UPV results, all of the OPSFRC and PFCS samples obtained (6670 percent) were of high quality and were of good value.

Seyed Meysam khoshnava et.al (2017): Green or bio composite materials are made up of biopolymers and natural fibres (NFS) derived from renewable resources, which aid in the reduction of nonrenewable waste, the reduction of raw material consumption, and the reduction of greenhouse gas emissions. The purpose of this work was to evaluate and develop a specific bio-composite in terms of mechanical properties, which was created using the lamination and compression moulding methods. There were several alternative layouts and varying numbers of layers used in this study to investigate the tensile and flexural capabilities of the KBFW/EFB hybrid reinforced $\mathrm{PHB}$ bio-composite.

S.A Kanalli et al. (2014) The researchers looked into the differences and similarities between polymer fibre reinforced concrete and regular concrete. Preliminary tests on mechanical properties, tensile strength, and flexural strength were carried out with varied proportions of polypropylene fibres, which resulted in a changing ratio of fibre dosage of 0.25 percent by volume of M20 grade concrete. A 0.75 percent fibre dose results in the strongest compressive, split tensile, and flexural strengths of concrete according to research.

Casein Ravi Kumar et al. (2013) Glass fibre reinforced concrete was researched for its strength and fire resistance. Glass fibre offers the benefit of having a stronger tensile strength and fire resistance, minimising the loss of damage to concrete buildings after a fire disaster. Glass fibres with a length of $450 \mathrm{~mm}$ are added to concrete in this study at a volume percentage of up to $1 \%$ to test its strength and fire resistance. Experiments demonstrate that increasing the amount of fibre in concrete increases compressive split tensile and flexural strength.
Pshtiwan N Shakor et al. a building project that looked at the usage of glass fibre reinforced concrete Trail tests for concrete with and without glass fibre are carried out in this study utilising cubes of various sizes to show variations in compressive and flexural strength. The GFRC is a fantastic alternative building material, according to the experimental test findings.

Yogesh Iyer Murthy et al. Glass fibre reinforced concrete performance was investigated. The compressive strength, flexural strength, and workability of concrete with various amounts of glass fibre as a fine aggregate substitute are investigated in this study. The increase in compressive strength is negligible, but the rise in flexural strength is considerable, as predicted, as the proportion of glass fibre increases. With a rise in glass fibre content, there is also a considerable drop in slump value.

Avinash Gornale et al. Glass fibre reinforced concrete's strength was studied. He utilised 0.03 percent glass fibres in M20, M30, and M40 grade concrete in his experiment. It was also discovered that when comparing Plain Concrete to Glass Fibre Reinforced Concrete, there is a steady rise in early strength for Compression and Flexural strength, as well as a rapid increase in ultimate strength for Split tensile strength.

A.M Shende et al. There has been some investigation into the strength qualities of steel fibre reinforced concrete for the M40 Grade. To investigate the compressive strength, flexural strength, and split tensile strength of steel fiber reinforced composites concrete (SFRC) containing fibres of $0 \%, 1 \%, 2 \%$ and $3 \%$ volume fraction of hook tain for M-40 grade of concrete with mix proportions of 1:1.43:3.04 and water cement ratio of 0.35 , a critical investigation of compressive strength, flexural strength, and split tensile strength of steel fibre reinforced concrete (SFRC) containing fibres of The information gathered was analysed and compared to a control specimen to determine its significance ( 0 percent fibre). The relationship between aspect ratio and compressive strength, flexural strength, and split tensile strength is illustrated in this diagram. It is obvious from the results data that the percent improvement in 28-day compressive strength, flexural strength, and split Tensile strength for M-40 Grade Concrete is significant.

Indrajit Patel et al. The impact of polyester fibres on the engineering characteristics of high-volume fly ash concrete was investigated. Mix design for M25, 


\section{EPRA International Journal of Research and Development (IJRD)}

30, 35, and M40 grade HVFA concrete with various percentages of class $\mathrm{F}$ fly ash $(50,55$, and 60 percent) is part of his work. Compressive, flexural, impact, and abrasion resistant engineering characteristics should be improved. At a rate of 0.25 percent by mass of cementitious material, $12 \mathrm{~mm}$ triangular shaped polyester fibre is used. The test findings for plain HVFA concrete for all grades with and without met the codal requirements for compressive strength at 3,7,28, and 56 days. The compressive strength of polyester fibres has improved by 12 to $15 \%$. At 28 and 56 days, fibre reinforced HVFA concrete exhibits a 16 to 23 percent improvement in flexural strength when compared to ordinary HVFA concrete, meeting the necessary criteria.

V.M. Southranjan et al. The usefulness of glass fibres as reinforcing agents in low-volume class F fly ash concrete was examined. An investigation of the reinforcing efficiency of glass fibre inclusion in low volume fly ash concrete up to a cement replacement level of 25 percent is presented in this paper. The results of the experimental tests revealed that mixing 25 percent fly ash with concrete containing 0.3 percent glass fibres resulted in the greatest compressive strength of 51.45 MPa after 28 days and the greatest flexural strength of $5.15 \mathrm{MPa}$ after the same amount of time. Using ultrasonic pulse velocity testing, it was possible to determine the quality of various concrete mixes as well as their conformity with the standard criterion for high-grade concrete.

K.Vijai et al. The features of glass fibre reinforced geopolymer concrete composites were explored in depth. When he tested materials that had glass fibres added to them, he looked at their density, compressive strength, split tensile strength, and flexural strength to see how well they performed. Glass fibres were added to the mix at concentrations of 0.01 percent, 0.02 percent, and 0.03 percent by volume of concrete, respectively, to achieve the desired results. On the basis of the test results, empirical equations for forecasting split tensile and flexural strength of glass fibre reinforced GPCC in terms of compressive strength were developed.

\section{CONCLUSION}

On the basis of past research in JFRC (jute fibre reinforced concrete), the literature review summarises the current level of knowledge in JFRC. It may be determined that jute fibre has a beneficial effect on the environment. If concrete is utilised in the right proportions and in the right way, it will most likely last for a long time. It is a feasible structural choice because of the benefits it provides. Greener and more environmentally friendly building is available. Fibre made from jute is a natural product that is both affordable and environmentally friendly. To improve the concrete's properties, add fibre.

The purpose of this review is to look at the possibilities of Coir fibre as a reinforcing component, as well as to report on the usage of Coir fibres in the works. Findings acquired from the above-mentioned research papers Publishers and authors. The goal of this study was to provide information to help with future study in this field despite this, coconut fibre as a supplement with good characteristics for the great majority of applications, concrete is unlikely to replace steel. Structures. Experiments and demonstration projects are taking place all around the world. Natural fibre augmentation has been proven to be a feasible option across the world. And costeffective alternative to traditional construction materials. According to our research and testing, coir fibre provides a lot of benefits. It has the potential to be utilised in place of steel for reinforcement or at the same time as steel. At the very least, it should be taken in combination with the former to get the benefits of both. Better strength, lower cost, and natural cooling are all advantages.

\section{REFERENCE}

1. H.A. Touting, Properties of polypropylene fibre reinforced silica fume expansive-cement concrete, Constr. Build. Mater. 13 (4) (1999) 171-177.

2. SAKINO Kenji, SUN Yuping : Stress-strain Curve of Concrete Confined by Rectilinear Hoop, Journal of structural and construction engineering Transactions of Architectural Institute of Japan, No.461; 1994.7, p. 95-104.

3. I Ramakrishna $G$, Sundararajan $T$. Impact strength of a few natural fibre reinforced cement mortar slabs: a comparative study. Cem Concr Compos 2005; 27:547-53.

4. E. Ismail, N. A. Zamani,2008, Tensile and impact behavior of hybrid extruded glass/natural fiber reinforced polypropylene composites., PP. (793796), Tun Hussein University of Malaysia, International Conference on Environmental Research and Technology.

5. Al-Khaiat H, Haque MN. Effect of initial curing on early strength and physical properties of lightweight concrete. Cem Concr Res 1998;28:859-66.

6. Al-Khaiat H, Haque MN. Effect of initial curing on early strength and physical properties of lightweight concrete. Cem Concr Res 1998;28:859-66.

7. ] D. Mazlan, ASM Abdul Awal, Properties of cement based composites containing oil palm stem as fiber reinforcement, Malays. J. Civil Eng. (2012) 107-117. 
8. ] Di Bella G, Fiore V, Valenza A. Natural fibre reinforced composite. In: Cheng $Q$, editor. Fiber reinforced composites. Hauppauge NY: Nova Science Publishers; 2012. p. 57-90.

9. Alengaram, U. J.; Jumaat, M. Z.; Mahmud, H. 2008. Ductility behavior of reinforced palm kernel shell concrete beams, European Journal of Scientific Research 23(3): 406-420.

10. S.P. Low, J.Y. Liu, P. Wu, Sustainable facilities: institutional compliance and the Sino-Singapore Tianjin Eco-city project, Facilities 27 (9) (2009) 268-386.

11. [1] S.A Kanalli, Ramu palankar, Bharat kumar, Praveen kumar, Prakash S.K "Comparitive study of polymer Fiber reinforced concrete with conventional concrete pavement" in IJRET, 2014.

12. [2] C. Selin Ravi kumar and T.S. Tandavamoorthy "Glass fiber concrete: investigation on strength and fire resistant properties" in IOSR-JMCE, 2013.

13. [3] Pshtiwan N Shakor, S.S Pimplikar " Glass fiber reinforced concrete use in construction" International Journal of technology and Engineering System Volume 2, March 2011.

14. [4] Yogesh Iyer Murthy, Apoorv sharda, Gourav jain "Perfomance of Glass fiber Rein forced concrete" International Journal of Engineering and Innovative Technology Volume1, Issue 6, june 2012.

15. [5] Avinash Gornale, $S$ Ibrahim quadric, $S$ Mehmood quardri ," Strength aspects of glass fiber reinforced concrete" in International Journal of scientific \& Engineering research, vol.3, July 2012 ISSN 2229-5518.

16. [6] A.M Shende, A.M Pande, M. Gulfam pathan, " Experimental study on steel fiber reinforced concrete for $M_{40}$ grade" in International refereed Journal of engineering and science.

17. [7] Indrajt Patel, C D Modherav, "Study effect of polyester fibers on engineering properties of high volume fly ash concrete" in Journal of engineering research and studies.

18. [8] V.M Southararajan , A. Siva kumar, “ Reinforcing efficiency of glass fibers in low volume class $F$ fly ash concrete" in Journal of civil engineering and construction technology.

19. [9] K.Vijay, R. Kumutha, B.G. Vishnuram, "Properties of glass fibre reinforced geopolymer concrete composites" in Asian Journal of civil engineering volume-13, 2012. 